\title{
Assurance views of testimony
}

[Manuscript version. Final version to appear in P. Graham, M. Fricker, D. Henderson, \& N. Pedersen, eds., Routledge Handbook of Social Epistemology (Routledge, forthcoming).]

\section{Philip J. Nickel, Eindhoven University of Technology p.j.nickel@tue.nl}

In this chapter, I describe the assurance view of testimonial knowledge and warrant and consider a significant challenge to the view. Excellent critical discussions of some earlier versions of the assurance view can be found in Lackey (2008, ch. 8) and Schmitt (2010). Here, I will emphasize literature that has appeared since 2010. Other recent critical discussions may be found in Shieber (2015, ch. 5) and Gelfert (2014, ch. 8).

\section{What is the assurance view?}

The assurance view is an epistemological position regarding testimonial knowledge and warrant. It holds that I can acquire knowledge from other people in virtue of the fact that when they tell me things, they thereby assure me that what they say is true, and in so doing provide me with an entitlement to rely on their authority. Suppose I am wondering whether Shakespeare's diaries are in the library, my friend Frost tells me that they are not (without further explanation), and I think I come to have knowledge of this fact as a result. On the assurance view, in such cases we may speak of a distinctively testimonial kind of epistemic warrant, based on the interpersonal act of assurance by which a speaker takes responsibility for the truth of what she says. Two theses are definitive of the assurance view: (I) acts of assurance are an important feature of testimony in our communicative practices; and (II) the practice of assurance allows for a distinctive and valid kind of epistemic warrant, and this is sometimes adequate to provide me with knowledge. A significant strand of scholarship, going back to an early moment in the revival of philosophical interest in the topic of testimony, has argued for similar claims (Welbourne 1979, Ross 1986).

A central goal of the assurance view is to provide an account of what is distinctive about testimonial warrant and knowledge. This is sometimes expressed as the aim of drawing a distinction between the way we normally treat testimony that $p$ as supporting $p$, and the way we treat evidence that $p$ as 
supporting $p$. If I believe Frost, I do not take his claim as a form of evidence that Shakespeare's diaries are not in the library, to be weighed in light of other evidence and experience. In this way, the assurance view is fundamentally opposed to reductive accounts of testimony which ground it fundamentally in personal experience and/or inference.

An important but infrequently discussed variant of the assurance view holds that assurance is closely tied to assertion itself and the norms governing assertion. Many philosophers hold that when we make an assertion, we invoke epistemic norms such as the norm that a person must only assert what she knows or has sufficient reason to believe (Goldberg 2015). This seems to generate a sort of norm-based entitlement in the hearer of testimony to believe what is said (Faulkner 2011; Goldberg 2011, 2015; Nickel 2013). Such views could be called norms of assertion views. By contrast, a more frequently discussed type of assurance view holds that assurances are a recognizable subspecies of assertion, similar to a promise, in which one makes a real commitment that backs up the warrant (cf. Schmitt 2010: 220-221). I will call these real commitment views.

One of the key arguments for both norms of assertion and real commitment versions of the assurance view is based on the remarkable fact that if a person has formed a belief on the basis of an assurance and his belief is challenged by a third party, he may "pass the buck" by holding the original speaker responsible for the truth and justification of the belief. ${ }^{1}$ For example, if Macy challenges me to show that Shakespeare's diaries are not in the library, I don't necessarily have to look for my own evidence for this claim (e.g., in the card catalogue or the library stacks). I can respond to her challenge by saying that I believe it because Frost told me so, passing the justificatory buck to Frost. This shows both that the act of responsibility-taking is often assumed as part of our conversational practices, supporting (I), and also that this has an epistemic aspect (since the "buck" being passed is the onus of providing an epistemic justification sufficient for one's claim to be maintained in the face of a challenge), supporting (II). It is also claimed that reductive accounts of testimony cannot explain epistemic buck-passing, because these accounts

\footnotetext{
${ }^{1}$ It could be that the meaning of buck-passing is a bit misunderstood. Harry S. Truman famously had a placard on his desk that said "The buck stops here," and he explained it in terms of the fact that he was ultimately the one who had to make difficult and uncertain decisions, rather than the fact that he possessed epistemic authority or had to provide a compelling justification after the fact. The 'buck' in poker is said to point to that person whose turn it is to deal the cards, not who has to pay. As Truman explained, "The President--whoever he is--has to decide. He can't pass the buck to anybody. No one else can do the deciding for him. That's his job." Farewell address, January 1953, as quoted at "The Buck Stops Here' Desk Sign," Harry S. Truman Library \& Museum, http://www.trumanlibrary.org/buckstop.htm, accessed 21 May 2016.
} 
imply that the audience is fundamentally personally responsible for how (s)he treats testimony as evidence for a belief she acquires.

The epistemic import of buck-passing is not immediately clear, but it can be understood such a way that it supports the warrant for the audience's belief in what a speaker says. The support for (II) could be further worked out as follows. Since the speaker and the audience know about assurance and buckpassing, the speaker will be aware that the audience may hold her accountable for the epistemic reasons for her claim, and (s)he will try to make sure only to make statements that are well-justified. This increases the reliability of what the speaker says, and the audience can grasp this fact by thinking about the situation, giving them an extra epistemic warrant to believe what is said (Faulkner 2011, ch. 6; Goldberg 2015: chs. 2-3). We can call this phenomenon "dependence-responsiveness" (Nickel 2012).

Some assertions seem to involve no act of responsibility-taking, or generate no actionable rights. For example, when a student makes an assertion on a written exam, or proposes an answer to a question posed in a classroom, (s)he is not generally supposing that others will use these assertions as definitive answers to open questions, no matter how much confidence (s)he has when answering. Many versions of the assurance view hold that assurance is different in kind from mere assertion (Welbourne 1979: 5). It is sometimes thought of as similar to a promise in that it has a specific recipient or recipients who come to have certain actionable rights as a result.

There are two ways in which the real commitment variant of the assurance view can explicate an idea of assurance distinct from assertion. The first corresponds to the content of the assurance, and the second to the parties whom the assurance relates. First, we can distinguish a particular mode of epistemic responsibility-taking that is characteristic of assurance, in the sense that the content of what one takes responsibility for is epistemic. Second, we can develop the idea that assurance has a distinctly second-personal character, so that, like promising, it relates specific persons. It is given to a specific person or persons, the audience, who are to be distinguished from others, mere bystanders or eavesdroppers, who are not proper objects of the assurance and may not take advantage of it for knowledge and justification in the same way. In the next two sections, I discuss these two ways of developing the real commitment view. 


\section{Assurance as epistemic responsibility-taking}

Krista Lawlor (2013) develops an account of assurance that is helpful in understanding what its particular character might be, as contrasted with ordinary assertion. ${ }^{2}$ She uses assurance to refer to cases in which one communicates 'I know $\mathrm{P}$ ' instead of merely asserting P. On her account, this is associated with a commitment by the speaker to "guarantee against reasonable alternatives" (10) in a way that is "good enough for anyone" (13) and is meant to end inquiry, at least provisionally. ${ }^{3}$ Mere assertions, by contrast, cover cases in which the speaker expects disagreement, such as when the committee chair states that "The federal stimulus package will reduce unemployment" (ibid.). We might also add the cases of assertions made by students on an exam or in a classroom, discussed above. Mere assertion is not meant to end inquiry or decide a question, and it issues no guarantee against reasonable alternatives.

On this view, the distinctive epistemic properties of assurance make it suitable for the transmission of knowledge via testimony: ${ }^{4}$ assurance is distinctive in that it makes a claim to knowledge. The point is not that one must have knowledge in order to transmit it. That point, if it is even defensible, ${ }^{5}$ would give no special role to assurance in securing transmission. For the assurance view, a role must be given to the assurance itself - as Lawlor understands it, the claim to knowledge - in the practice of testimony, and this role must be sufficient, under the right conditions, to provide knowledge in the audience. For that we need a further explanation of how this is supposed to create epistemic warrant in the audience.

A speaker's adding a mere verbal guarantee does not put the hearer in a better epistemic position, for the speaker could be lying, careless or incompetent. It is only when the guarantee goes along with a particular epistemic and practical state in the speaker that the guarantee makes the hearer better off epistemically. Consider an example from Lawlor, in which Henrik looks in the refrigerator and wonders if the leftovers there are still edible, and Serena

\footnotetext{
${ }^{2} \mathrm{Nb}$. Lawlor's interest is in developing the idea of assurance, rather than advancing the assurance view of testimony. She remains agnostic about the latter.

${ }^{3}$ Here a reasonable alternative is, approximately, a possible state of affairs that would falsify the statement, is not obviously incompatible with the observed evidence, and is salient to reasonable people in the context. Ruling out reasonable alternatives is often held as a condition on knowledge.

${ }^{4}$ When I talk about "transmission" here, I am referring to a general phenomenon in which the speaker conveys knowledge to a hearer, not a rigid principle according to which testimonial knowledge always originates from a source who has knowledge (cf. Lackey 2008, ch. 2).

${ }^{5}$ Well-known challenges to this sort of idea can be found in Graham 2006: 112-113, Lackey 2008, ch. 2.
} 
assures him that they are (Lawlor 2013: 19). How can Henrik know on this basis that the leftovers are still edible (assuming he cannot verify the matter without taking a bite - perhaps his sense of smell is impaired)?

Intuitively, it seems that for Henrik to get knowledge from Serena, he must also have reason to trust her, so that lies and incompetence are ruled out. Accounts of assurance are frequently paired with accounts of trust (Faulkner 2011, Hinchman 2005; McMyler 2011). There are two dimensions of the reasons for trusting somebody, corresponding to "external" and "internal" aspects of the trust relation. The first dimension is that Serena is trustworthy, so that Henrik's trust correctly represents real dispositions and capacities of Serena, which back up his trust. The second dimension is that Henrik grasps or has access to reasons to believe or expect that Serena is trustworthy, so that his trust is suitably well-founded.

Some accounts of trust and its epistemology play up the internal aspect of reasons for trust, emphasizing that the audience should have sufficient positive reason to set aside reasonable doubts about the motives and competence of the speaker. This is helpful for allowing audience greater control and (shared) responsibility, in terms of what beliefs they do or do not acquire through testimony. The underlying idea is that trust should not be blind. However, the grasp of reasons for trust must not then require unrealistic intellectual capacities. Is this a realistic requirement on reasons for trust?

Perhaps something like the following story would make this a realistic requirement. In normal conditions, humans are sometimes capable of accurately representing the interests and practical reasons that would lead others to be trustworthy, and thus less prone to lie or be careless with the truth. People are often highly sensitive to whether the interests of others are coincident or non-coincident with their own. This is bound up with the ability to construct a mental model of the intentional behavior of others in terms of their goals and interests, which is required for interpretive and predictive purposes in a social world. (In everyday contexts we try not to rely too much on the assurances of those about whose interests we can make no such model.) For those who are not equipped with such representational capacities, it may also be plausible to adopt a double standard about the basing dimension of trust in some contexts. For example, one could hold that young children who trust their parents need not have a grasp of positive reasons for doing so in order for them to take advantage of the assurances 
their parents give. But sophisticated adults in a professional environment might be required to have such a grasp in order for their trust to be suitably based.

On such a view, it seems as if the engine of testimonial justification is trust and trustworthiness, rather than assurance. But in fact, the two elements work together, in a way broadly suggested by Hinchman $(2012,2014)$. Consider a far-fetched variant of the case we have been considering which illustrates the point that without assurance, trust and trustworthiness alone are not sufficient for testimonial warrant. Suppose that Henrik trusts Serena on an adequate basis, and that Serena is sufficiently trustworthy in the domain of their shared interactions. Henrik has a technologically advanced brain-wave detector that can tell him some of Serena's occurrent beliefs, and the detector now tells him accurately that her occurrent belief while looking at the leftovers is that they are still edible. Reading Serena's occurent beliefs is surely different from hearing Serena make an assurance that the leftovers are still edible. For if Henrik just reads Serena's brain waves, he might not be able to reasonably conclude that the leftovers are really still edible. Because of his different context or history, he might have different standards from Serena, either of edibility or what counts as sufficient evidence for edibility. (Maybe he recently had food poisoning!) But if Serena attunes her assurances to his standards, which often happens in ordinary talk, this barrier can be overcome. The underlying idea is that when Serena provides an assurance, she is not merely reporting an occurrent belief. She is representing herself "as helping him to know in the context of his epistemic needs, not merely in the context of her own" (Hinchman 2013, 618, pronouns changed). This is, presumably, part of the commitment or responsibility she undertakes in assurance. Conversely, this implies that even when Serena does not believe something herself, she can still rightfully assure Henrik of it, because she knows that it meets his standards. In such a case, reading Serena's brainwaves would not serve Henrik's epistemic needs.

To sum up: the real commitment view can be specified, in part, by explicating the distinctive content of epistemic responsibility-taking made in an assurance. Lawlor (op cit.) describes this as a commitment by the speaker to defend the testimonial claim against reasonable alternatives, and thereby to provide conclusive backing for a testimonial belief in the audience. Such a commitment is of questionable value to an audience if they have no trust in the speaker; accounts of trust are, for this reason, often given alongside accounts of assurance. However, these accounts may threaten to make the 
role of assurance as a distinctive form of commitment-taking epistemically extraneous, because it is trust and the reasons for it, rather than a special kind of guarantee, that make it reasonable to believe what somebody else says. Hinchman's (op cit.) account of how assurance plays a distinctive role in providing warrant - on which a speaker takes responsibility for adjusting what is assured to the epistemic context of the audience - helps respond to this worry.

\section{Assurance as person-to-person responsibility-taking}

Some philosophers see a crucial role for assurance, not merely in the distinctive kind of knowledge claim that it makes or in the way that it can be attuned to the epistemic context of the audience, but rather in the fact that assurance is a person-to-person act of responsibility-taking. This "secondpersonal" view of assurance, set out in detail by McMyler (2011), holds that assurance is expressed in an interpersonal speech act, telling, with an intended recipient. This type of view, building on the work of Welbourne (1979), Ross (1986), Moran (2005), and Hinchman (2006), is the one perhaps most often associated with the label "assurance view of testimony."

The second-personal character of assurance, according to McMyler, is to be explained in terms of the speaker's act of assuming responsibility in relation to a specific audience. McMyler, applying Darwall's (2006) account of second personal reasons, claims that a second-personal reason only has its force by being given by $A$ to $B$ and recognized by $B$ as such, where $A$ takes responsibility for giving the reason and is recognized by $B$ as having the authority to do so (McMyler 2011, 145). Applied to testimony, second-personality captures what is distinctive about testimonial justification. Testimonial assurance is given to a specific person or persons, the audience, who must recognize it as being given to them. Just as those who have merely overheard a promise are not in a position to demand its fulfillment, mere bystanders and eavesdroppers do not have the same warrant as the intended audience of an act of assurance, because they are not the ones to whom the relevant reason is given. Whereas evidence is the kind of thing that is available to anybody who observes it as a reason for belief, testimonial assurance is only available to those to whom it is offered. Others who witness the assurance but are not its intended audience may treat it as evidence, but they cannot treat it in the way it is offered to the intended audience, as expressing authority. 
To see why this conception of assurance is attractive, let us briefly recapitulate the main argument for the assurance view. The essence of testimonial warrant and knowledge lies in the fact that in testifying we offer an assurance to the audience. This assurance consists of taking responsibility for the truth of what is said, which is to be understood in terms of one's taking on the burden of having appropriate reasons for what one says, and being willing to produce or defend what is said when challenged. The justificatory role of assurance is thus conceptually linked with the phenomenon of epistemic buck-passing. When I acquire a belief by relying on Frost's testimony, and this belief is reasonably called into question, it seems appropriate to question or criticize Frost and not only me. If Frost can't produce the goods when challenged, he is to be criticized for speaking insincerely or without sufficient evidence. In this way the "buck" of justification is passed to Frost and stops with him, unless of course he obtained his own information through testimony, in which case the call for justification may be carried back still further.

McMyler's theory suggests that only a view on which second-personal epistemic authority is offered and accepted can adequately explain the phenomenon of epistemic buck-passing. If testimonial authority were reasongiving but not second-personal, it would have to be in virtue of the evidence it provided for what was testified. But in that case, the audience would be responsible for gathering this evidence itself. Then it would also make sense for them to defend their testimonial beliefs themselves. Epistemic buckpassing would be difficult to explain or justify. It is only in virtue of the act of responsibility-taking by the speaker, and the recognition of this by the audience, that transmitting requests for justification to the speaker becomes legitimate. Reductive or evidential views of testimony cannot explain this phenomenon.

As I see it, however, this important point need not imply that mere bystanders have no right to take up offers of testimonial authority, or to demand justification from the speaker if there are doubts about the statements made on the basis of that authority. ${ }^{6}$

\footnotetext{
${ }^{6}$ McMyler appeals to the intuition that mere bystanders and eavesdroppers do not have the right of buckpassing, to support the restriction of assurance-based warrant to the intended audience. Lawlor disputes this, holding that mere bystanders and eavesdroppers have the same rights of challenge as the intended audience (Lawlor 2013: 22). There is some empirical evidence for the hypothesis that mere bystanders and eavesdroppers are not ordinarily attributed the right of buck-passing (Turri 2015). However, one might explain this hypothesis in terms of privacy norms rather than epistemic factors: demanding justification from somebody who wasn't speaking to you violates informational privacy (Nickel 2013). It doesn't have to do with warrant.
} 


\section{The challenge to assurance views}

A persistent challenge for assurance views is that although they may capture in a satisfying way some key aspects of the phenomenology of relying on testimony, the fact that testifiers assume responsibility for what they say does not provide an adequate warrant for testimonial belief. Put another way: even if the speaker's assurance gives the audience the entitlement to believe what is testified from a conversational or moral point of view, this is far from adequately ensuring that the audience comes to have knowledge in so doing. Issuing such a guarantee is compatible with many plausible, non-hyperbolic scenarios on which the belief is false.

Joseph Shieber describes this as a failure to satisfy a fundamental epistemic requirement, which he calls the "Adequacy Goal": the goal of "maximiz[ing] the likelihood that the recipient believe a proposition only if that proposition is true" $(2015,5)$. The assurance view seems to license belief-adoption that it should not license from this austerely epistemological point of view. On the other hand, most beliefs, and certainly most testimonial beliefs, carry a nonzero risk of being false. Testimony adds a source of risk - other people - that can only be avoided completely by kicking away reliance on testimony completely. This makes it clear that the best way of satisfying Shieber's Adequacy Goal is to maintain no testimonial beliefs whatsoever. This is absurd as a core principle of guidance in an epistemology of testimony. A more adequate Adequacy Goal would start by acknowledging that I must form and maintain many of my beliefs on the basis of testimony, and that I should do so, if possible, in ways that reliably produce true beliefs. ${ }^{7}$ The more relevant form of the challenge, then, is this: assurance views, by licensing us to rely on assurances (at least in situations where we have reason to trust the speaker) on the basis of the speaker's fundamental authority, endorse a form of testimonial belief-formation that does not reliably produce true beliefs.

A concrete case helps to bring out the implications of the view more forcefully. In 2011, the Dutch social psychologist Diederik Stapel, dean of the School of Social and Behavioral Sciences at his faculty, was determined to have based much of his scientific work on fraudulent data (Bhattacharjee 2013).

Colleagues and PhD students who had not themselves participated in the fraud had nonetheless collaborated with him on various studies and (prior to the

\footnotetext{
${ }^{7}$ This is obviously different from a criterion for assessing whether a person has knowledge or conclusive warrant for a belief.
} 
revelations about him) plainly believed many of his statements on testimony, without performing independent checks sufficient to reveal discrepancies in his account. After all, he satisfied reasonable criteria for trustworthiness: he was highly trained and experienced, his work had been vetted by scientific journals, and he had a reputation to defend. His assurances had an excellent pedigree.

Assurance views seem to tolerate or even endorse Stapel's colleagues' acceptance of his assurances, prior to the revelation of fraud. But more importantly, they seem committed to the claim that any adequate account of testimony and testimonial belief must endorse such cases of acceptance. If epistemologists require independent checks and verification in order to restrain testimonial belief and epistemic authority so that such reliance counts as epistemically unreasonable, this is equivalent to rejecting testimonial belief itself from the point of view of epistemology. This seems to be a problematic commitment of the assurance view. It seems more attractive to adopt a more modest view of the appropriate role of authority in testimonial belief, one on which warranted reliance on testimony in high-standards contexts (such as the modern practice of science) requires - and therefore must allow for substantial independent checks and reasoning that would greatly diminish the role of assurance in our practices.

\section{References}

Yudhijit Bhattacharjee. The Mind of a Con Man. New York Times Magazine, April 26, 2013.

Stephen Darwall. The Second Person Standpoint. Cambridge, Mass.: Harvard University Press (2006).

Paul Faulkner. Knowledge on Trust. Oxford: Oxford University Press (2011). 
Axel Gelfert. A Critical Introduction to Testimony. London: Bloomsbury Academic (2014).

Sanford Goldberg. Putting the Norm of Assertion to Work: The Case of Testimony. In J. Brown \& H. Cappelen, eds. Assertion: New Philosophical Essays. Oxford: Oxford University Press (2011): 175-195.

-. Assertion: On the Philosophical Significance of Assertoric Speech. Oxford: Oxford University Press (2015).

Peter Graham. Can Testimony Generate Knowledge? Philosophica 78 (2006): 105-127.

Edward S. Hinchman. Telling as Inviting to Trust. Philosophy and Phenomenological Research 70:3 (2005): 562-587.

-. Can Trust Itself Ground a Reason to Believe the Trusted? In A Symposium on Paul Faulkner's Knowledge on Trust. Abstracta, Special Issue VI (2012): 4783.

-. Assertion, Sincerity, and Knowledge. Noûs 47:4 (2013): 613-646.

-. Assurance and Warrant. Philosophers' Imprint 14: 17 (2014): 1-58.

Jennifer Lackey. Learning from Words. Oxford: Oxford University Press (2008).

Krista Lawlor. Assurance: An Austinian View of Knowledge and Knowledge Claims. Oxford: Oxford University Press (2013).

Benjamin McMyler. Testimony, Trust, and Authority. Oxford: Oxford University Press (2011).

Richard Moran. Getting Told and Being Believed. In J. Lackey \& E. Sosa, eds. The Epistemology of Testimony. Oxford: Oxford University Press (2006): 272306.

Philip J. Nickel. Trust and Testimony. Pacific Philosophical Quarterly 93:3 (2012): 301-316. 
-. Testimonial Entitlement, Norms of Assertion, and Privacy. Episteme 10:2 (2013): 207-217.

Angus Ross. Why Do We Believe What We Are Told? Ratio 1 (1986): 69 - 88.

Frederick F. Schmitt, The Assurance View of Testimony. In A. Haddock, A. Millar \& D. Pritchard, eds. Social Epistemology. Oxford: Oxford University Press (2010): 216-242.

Joseph Shieber. Testimony: A Philosophical Introduction. London: Routledge (2015).

John Turri. Assertion and Assurance: Some Empirical Evidence. Philosophy and Phenomenological Research 90:1 (2015): 214-222.

Michael Welbourne. The Transmission of Knowledge. The Philosophical Quarterly 29, 114 (1979): 1-9. 